\title{
Desgarramento e pontuação em textos de vestibulandos
}

\section{Detachment and punctuation in students' compositions}

\author{
Violeta Virginia Rodrigues* \\ David Novaes Cidade**
}

\begin{abstract}
RESUMO
O fenômeno do desgarramento permite-nos aceitar a possibilidade de que "subordinadas" ocorram sintaticamente independentes de suas principais e separadas destas por ponto final. Segundo Decat (2011), desgarramento é o fenômeno pelo qual se identificam unidades de informação que ocorrem soltas nas estruturas linguísticas e o ponto é o principal índice deste fenômeno na escrita. Partimos, portanto, da hipótese de que o uso não-convencional (TENANI; SONCIN, 2010) desse sinal de pontuação, de forma a isolar e realçar as "subordinadas" que tradicionalmente comporiam um período composto, não só modifica a estrutura sintática do período como também evidencia uma intenção comunicativa do escrevente. Assim, adotamos a proposta funcionalista de que relativas apositivas e circunstanciais constituem casos de hipotaxe e não de subordinação, e analisamos usos dessas estruturas materializadas de forma desgarrada em um corpus composto de 197 redações do site educacao.uol.com.br (CIDADE, 2020). Os resultados encontrados confirmam os de Rodrigues (2019).
\end{abstract}

Palavras-chave: Funcionalismo; hipotaxe; desgarramento, função textualdiscursiva; pontuação.

Recebido em 16 de setembro de 2020.

Aceito em 13 de novembro de 2020.

DOI: http://dx.doi.org/10.18364/rc.2021n61.476

*Universidade Federal do Rio de Janeiro, violetarodrigues@uol.com.br, https://orcid.org/0000-0003-1789-5675

**Universidade Federal do Rio de Janeiro, david_letras@live.com

Confluência. Rio de Janeiro: Liceu Literário Português, n. 61, p. 124-156, jul.-dez. 2021 


\section{ABSTRACT}

The detachment phenomenon allows us to accept the possibility of subordinate clauses occurring syntactically independent from their main clauses, being seperate from them through a full stop punctuation mark. According to Decat (2011), detachment is the phenomenon through which information units are identified as occurring loosely in linguistic structures and the full stop punctuation mark is the main indication of it on writing. Thus, our hypothesis is based on the idea that the non conventional use of such punctuation mark (TENANI; SONCIN, 2010), which isolates and enhances the subordinate clauses that traditionally constitute a compound period, not only modifies the syntactic structure of the period but also shows a communicative intention of the writer. In this manner, we adopt the funcionalist proposal that supports the idea that apositive relative clauses and circumnstancial clauses are cases of hypotaxis and not subordination. We also analyze the uses of such structures in a detached materialization, collecting the examples from a corpus composed of 197 writing compositions taken from educacao.uol.com.br (CIDADE, 2020). The results found though the present analysis confirm the ones previously indicated by Rodrigues (2019).

Keywords: Functionalism; hypotaxis; detachment; textual discursive function; punctuation.

\section{Introdução}

Sabemos que o ensino de gramática normativa no Brasil, em geral, adota métodos que abordam a língua portuguesa de forma descontextualizada, centrando-se, normalmente, no nível sentencial. Um aspecto reiterado por essa visão é o da dependência sintática de orações subordinadas às principais. Segundo a gramática tradicional, as subordinadas devem estar sempre junto de suas principais, pois são sintaticamente dependentes destas. Com exceção da vírgula, nenhum outro sinal de pontuação é prescrito no âmbito do período composto para separar tais orações.

Há estudos de linha funcionalista, entretanto, que identificam o uso de orações "subordinadas" separadas das principais, isto é, ocorrendo sintaticamente independentes e separadas por ponto $/ . /{ }^{1}$ de suas principais.

1 Decidimos, nesse trabalho, adotar a forma escrita seguida da realização gráfica dos sinais de pontuação para facilitar a identificação do sinal referido.

Confluência. Rio de Janeiro: Liceu Literário Português, n. 61, p. 124-156, jul.-dez. 2021 
Decat $(1993,2011)$ chama esse fenômeno pelo qual se identificam unidades de informação que ocorrem soltas nas estruturas linguísticas de desgarramento. Para descrevê-lo melhor, faz-se necessário relacioná-lo com os processos sintáticos de conexão de orações e com o uso dos sinais de pontuação.

$\mathrm{Na}$ perspectiva tradicional, apenas dois processos sintáticos são apresentados para a composição do período composto: a coordenação e a subordinação. Tais conceitos não dão conta da ocorrência desgarrada de orações "subordinadas" adjetivas explicativas e adverbiais foco desse estudo. Isso porque o processo sintático que estrutura essas orações é a hipotaxe e não a subordinação, segundo a perspectiva funcionalista por nós adotada (RODRIGUES, 2010, 2017).

Na teoria funcionalista, a hipotaxe (HOPPER; TRAUGOTT, 1993) é o processo em que uma cláusula se combina com outra - sendo essa denominada cláusula núcleo - sem estabelecer uma relação de constituência com ela, ou seja, a cláusula hipotática é satélite de uma cláusula núcleo. Há, portanto, uma relação de núcleo-satélite (MATTHIESSEN; THOMPSON, 1988) no cerne desse processo sintático, o que, segundo Decat (1993, 2011), favorece o uso dessas estruturas como desgarradas.

$\mathrm{Na}$ maioria das gramáticas tradicionais, os usos dos sinais de pontuação são associados à pausa e à entoação, desconsiderando-se, muitas vezes, o fato de a pontuação ser um recurso da modalidade escrita da língua.

Assim, relacionando-se o conceito de subordinação e o tratamento dado aos usos dos sinais de pontuação pelas gramáticas tradicionais, casos como o da cláusula (1), destacada em negrito, seriam considerados "errados", sendo a pontuação empregada antes do verbo "oferecendo" um desvio às regras de bom uso da língua escrita:

(1) O Governo, portanto, deve investir amplamente na educação da sociedade e pontualmente na conscientização da família acerca dos mecanismos de coibição contra a violência sexual. Oferecendo incentivo às empresas para financiar campanhas e projetos em prol dos adolescentes de baixa renda que vivem em situações preocupantes. 
Autores como Tenani; Soncin (2010) abordam o uso não-convencional da pontuação para abarcar ocorrências dos sinais de pontuação que apresentam motivação enunciativa. Adotando-se a perspectiva das autoras, podemos analisar o ponto /. / empregado no exemplo (1), como um uso nãoconvencional que revela uma intenção discursiva do escrevente e que serve, portanto, para indicar uma estrutura desgarrada, marcando sua independência sintática em relação à estrutura anterior. Além dessas autoras, Dahlet (2006) também elucida considerações relevantes sobre a pontuação.

Segundo ela, a pontuação é operadora sintática e semântica e, portanto, consubstancial à produção textual e não, acessória a ela. Dahlet (2006) chama de ponto /. / de argumentação ao ponto /. / utilizado para destacar a cláusula desgarrada antes mostrada.

Então, adotando-se a proposta funcionalista de que as adjetivas explicativas e as adverbiais constituem casos de hipotaxe e não de subordinação e, ainda, partindo-se da ideia que a pontuação é operadora sintática e semântica, observando-se os usos efetivos empregados pelo escrevente, analisa-se o desgarramento como fenômeno favorecedor da argumentação textual em redações de vestibulandos.

Foram analisados para esse estudo 197 textos do banco de redações do site educacao.uol.com.br. e neles foram encontrados 19 casos de cláusulas desgarradas. Nossa hipótese é a de que o desgarramento é um fenômeno que contribui para argumentação dos vestibulandos, conforme atesta Rodrigues (2019) para outros corpora.

Além dessa introdução, esse artigo recupera em 1 algumas considerações a respeito da subordinação na Gramática Tradicional, bem como em 2 sobre pontuação. Em 2, dá-se mais ênfase à abordagem enunciativa dos usos dos sinais de pontuação. Em 3, apresentamos a perspectiva funcionalista de conexão de orações, destacando a hipotaxe, enfatizando o fenômeno em estudo - o desgarramento. Em 4 mostramos a metodologia do trabalho, a análise dos dados e os resultados encontrados. Finalizamos com nossas conclusões seguidas das referências utilizadas. 


\section{Subordinação na Gramática Tradicional}

A abordagem da subordinação nas gramáticas de Cunha; Cintra (2001), Luft (2002), Bechara (2003) e Rocha Lima (2006) reforça a noção de que os períodos compostos por subordinação têm sempre a oração principal e uma ou mais orações subordinadas que a complementam. As orações subordinadas, portanto, desempenhariam sempre uma função sintática junto às principais, sendo dependentes sintaticamente destas e, portanto, não podendo existir sozinhas nessa perspectiva. O quadro 1 a seguir elucida as definições das gramáticas antes elucidadas:

Quadro 1. Definições de subordinação na GT

\begin{tabular}{|l|l|}
\hline $\begin{array}{l}\text { Cunha; Cintra } \\
\text { (2001, p. 594) }\end{array}$ & $\begin{array}{l}\text { "As orações sem autonomia gramatical, isto é, as orações que } \\
\text { funcionam como termos essenciais, integrantes ou acessórios de outra } \\
\text { oração, chamam-se subordinadas. O período constituído de orações } \\
\text { subordinadas e uma oração principal denomina-se composto por } \\
\text { subordinação.” }\end{array}$ \\
\hline $\begin{array}{l}\text { Luft } \\
(2002, \text { p. 79) }\end{array}$ & $\begin{array}{l}\text { "(..) subordinada é a oração que depende de outra (dita principal). } \\
\text { correlativos: não há principal sem subordinada, nem subordinada sem } \\
\text { principal.” }\end{array}$ \\
\hline $\begin{array}{l}\text { Bechara } \\
(2003, \text { p. 561-562) }\end{array}$ & $\begin{array}{l}\text { “(..) o conjunto complexo que a noite chegou não passa de um termo } \\
\text { sintático na oração complexa } O \text { caçador percebeu que a noite chegou, } \\
\text { que funciona como objeto direto do núcleo verbal percebeu. Estas } \\
\text { unidades transpostas exercem função própria de meros substantivos, } \\
\text { adjetivos e advérbios, razão por que são assim classificadas na oração } \\
\text { complexa. (..) Assim, apesar destas considerações, esta gramática } \\
\text { respeitará o peso da tradição e verá (...) como oração subordinada o } \\
\text { complexo unitário correspondente a uma função sintática exercida por } \\
\text { substantivo, adjetivo ou advérbio.” }\end{array}$ \\
\hline $\begin{array}{l}\text { Rocha Lima } \\
(2006, \text { p. 261) }\end{array}$ & $\begin{array}{l}\text { "No período composto por subordinação, há uma oração principal, que } \\
\text { traz em si, como dependente, outra ou outras. Dependentes, porque cada } \\
\text { uma tem seu papel como um dos termos da oração principal.” }\end{array}$ \\
\hline
\end{tabular}

Confluência. Rio de Janeiro: Liceu Literário Português, n. 61, p. 124-156, jul.-dez. 2021 
Observa-se, pelo quadro 1 que, em geral, os gramáticos tradicionais se utilizam da noção de dependência sintática e semântica para conceituar a subordinação. Cunha; Cintra (2001), por exemplo, afirmam que as subordinadas não têm nenhuma autonomia gramatical, pois funcionam como "termos essenciais, integrantes ou acessórios de outra oração".

Luft (2002), por sua vez, marca uma suposta interdependência entre subordinadas e principais, valendo-se tanto do critério sintático, quanto do semântico. Já Bechara (2003) afirma que, na subordinação, não há propriamente um período composto, mas, sim, uma "oração complexa", porque subordinada e principal juntas comporiam uma única unidade linguística.

Percebe-se, então, que os critérios adotados em Cunha; Cintra (2001), Luft (2002) Bechara (2003) e Rocha Lima (2006) se limitam ao nível da sentença. Sendo assim, um fenômeno como o desgarramento fica fora do escopo de suas análises.

Portanto, nessa perspectiva, as subordinadas são constituintes de uma principal - não podendo ocorrer isoladas dessa - e, por isso, não deveriam se realizar separadas por pontuação terminativa (sinais de grande amplitude, conforme DAHLET, 2006, p. 56), isto é, o ponto /./, a exclamação /!/, a interrogação /?/ e as reticências /.../. No entanto, como já mencionado, as cláusulas que se materializam desgarradas contrariam essa afirmação.

\section{Pontuação}

A princípio, é possível afirmar que não há consenso sobre o fazer pontuacional (DAHLET, 2006) na abordagem do tema pelos gramáticos tradicionais. Os critérios que norteiam suas definições são variáveis.

Cunha; Cintra (2001), por exemplo, relacionam a pontuação à oralidade, afirmando que essa serviria para "reconstituir aproximadamente o movimento vivo da elocução oral", já que a língua escrita não dispõe "dos inumeráveis recursos rítmicos e melódicos da língua falada". Esses gramáticos dividem os sinais de pontuação em pausais - que marcam pausa 
- e melódicos - que têm como "função essencial marcar a melodia, entoação" (CUNHA; CINTRA, 2001, p. 643).

Luft (2002), por sua vez, assevera que a pontuação é o "sistema de sinais com que se representam os fonemas supra-segmentais, principalmente as pausas" (LUFT, 2002, p. 240). Ora, fonemas suprasegmentais têm relação com os aspectos do discurso ligados à prosódia, como, por exemplo, a entonação, a melodia, a ênfase.

Já Rocha Lima (2006) afirma que há na língua "pausas rítmicas" que são assinaladas na pronúncia por entoações características e na escrita por sinais especiais. As pausas do discurso escrito são categorizadas, segundo ele, em: 1) "pausa que não quebra a continuidade do discurso, indicativa de que a frase ainda não foi concluída"; 2) pausa que indica término do discurso ou de parte dele; 3) pausa que serve para frisar uma intenção ou estado emotivo" (ROCHA LIMA, 2006, p. 458).

Evidencia-se por meio dessas afirmações que não há aprofundamento sobre o que é e como se dá o fazer pontuacional de fato na Língua Portuguesa. Ao aproximarem fala e escrita em suas definições, os gramáticos desconsideram as especificidades da língua escrita e da língua oral. Há um grande continuum entre fala e escrita, no qual os gêneros textuais escritos se inserem, ou seja, existem textos da modalidade escrita produzidos para serem oralizados e textos que nunca o serão.

Diferentemente dos autores supracitados, Bechara (2003) conceitua o fazer da pontuação a partir de suas efetivas funções nos usos linguísticos. Ancorado na teoria de Catach (1994), o gramático afirma que os sinais de pontuação exercem funções relacionadas à sintaxe, à gramática, à entoação e à semântica da língua. Tais sinais seriam "unidades sintáticas, 'sinais de orações' e 'sinais de palavras', podendo comutar com tais unidades alfabéticas, substituí-las e tomar de empréstimo seu valor" (BECHARA, 2003, p. 604).

A proposta de Bechara (2003) é a mais próxima a de Dahlet (2006), que adotamos neste estudo; esta autora tenta contemplar os diversos aspectos relativos ao fazer pontuacional. Bechara (2003) inclusive explicita que "é bem 
provável, que" certos tipos de pontuação "pertençam à iniciativa e decisão do autor no seu desejo de levar ao texto algo mais de expressividade, de contorno melódico, rítmico e entoacional, além das palavras e construções utilizadas" (BECHARA, 2003, p. 605).

Essa afirmação do gramático permite-nos interpretar que o uso do ponto /./ como índice do desgarramento, por exemplo, é fruto da intenção comunicativa do escrevente. O ponto /./ de argumentação (DAHLET, 2006), que realça/destaca as cláusulas desgarradas, é uma marca evidente de "expressividade" a favor da argumentação. No quadro a seguir, encontram-se algumas das definições para ponto /./ presentes nessas gramáticas.

Quadro 2. Abordagem do ponto /./ na GT

\begin{tabular}{|c|c|c|c|c|}
\hline Gramático & $\begin{array}{l}\text { Ponto } \\
\text { final }\end{array}$ & $\begin{array}{c}\text { Ponto } \\
\text { parágrafo }\end{array}$ & $\begin{array}{c}\text { Ponto } \\
\text { simples }\end{array}$ & Definição \\
\hline $\begin{array}{l}\text { Cunha e Cintra } \\
(2001, \text { p. } 650)\end{array}$ & $\mathrm{X}$ & $\mathrm{X}$ & $\mathrm{X}$ & $\begin{array}{l}\text { O ponto: “(...) assinala uma pausa } \\
\text { máxima na voz depois de um grupo } \\
\text { fônico de final descendente. Emprega- } \\
\text { se, pois, fundamentalmente, para } \\
\text { indicar o término de uma oração } \\
\text { declarativa, seja ela absoluta, seja a } \\
\text { derradeira de um período composto.” }\end{array}$ \\
\hline Luft (2002) & $\mathrm{X}$ & / & $\mathrm{X}$ & Não há definições. \\
\hline $\begin{array}{l}\text { Bechara } \\
(2003, \text { p. 605) }\end{array}$ & $X$ & $X$ & $X$ & $\begin{array}{l}\text { “(...) se a oração seguinte constitui } \\
\text { novo conjunto de ideias, ou mudança } \\
\text { de interlocutor de diálogo, será escrito } \\
\text { na outra linha e terá o seu final } \\
\text { marcado pelo ponto parágrafo." } \\
\text { "O ponto simples final, que é dos } \\
\text { sinais que denota maior pausa, } \\
\text { serve para encerrar os períodos que } \\
\text { terminem por qualquer tipo de oração } \\
\text { que não seja interrogativa direta, a } \\
\text { exclamativa e as reticências." }\end{array}$ \\
\hline
\end{tabular}




\begin{tabular}{|c|c|c|c|c|}
\hline Gramático & $\begin{array}{l}\text { Ponto } \\
\text { final }\end{array}$ & $\begin{array}{c}\text { Ponto } \\
\text { parágrafo }\end{array}$ & $\begin{array}{c}\text { Ponto } \\
\text { simples }\end{array}$ & Definição \\
\hline $\begin{array}{l}\text { Rocha Lima } \\
(2006, \text { p. } 466 \\
-467)\end{array}$ & $\mathrm{X}$ & $\mathrm{X}$ & X & $\begin{array}{l}\text { Ponto simples: "final das orações } \\
\text { independentes e no final de cada } \\
\text { oração ou período que, associados } \\
\text { pelo sentido, representarem } \\
\text { desdobramentos de uma só ideia } \\
\text { central -, sem mudança sensível, } \\
\text { portanto, do teor do conjunto." } \\
\text { Ponto parágrafo: "é de rigor quando, } \\
\text { concluída uma unidade de composição, } \\
\text { se vai iniciar outro de teor diferente". } \\
\text { Ponto final: "quando com ele se } \\
\text { encerra definitivamente o trecho" }\end{array}$ \\
\hline
\end{tabular}

Percebe-se, pelo quadro 2, que não há consenso sobre os usos do ponto /./. Os autores ora se baseiam na oralidade, como Cunha; Cintra (2001), ora se baseiam na posição ocupada pelo sinal dentro da oração, conforme Bechara (2003) e Rocha Lima (2006). Assim, parecem não levar em conta que a pontuação é "consubstancial à produção textual, ou seja, simultânea e não consecutiva, já que a pontuação é operadora sintática e semântica" (DAHLET, 2006, p. 36-37).

Ainda em Bechara (2003), observa-se outro problema. Se os sinais de pontuação exercem funções no todo do registro escrito (como apontado pelo próprio autor), não há necessidade de distinção entre "ponto-parágrafo" e "ponto-final". A função do ponto /./ nas duas definições destacadas no quadro 2 é separar períodos. Ao postular duas categorias para o mesmo o uso do ponto /./, o gramático prioriza o critério posição em detrimento da função exercida pelo sinal, desconsiderando, assim, suas próprias postulações a respeito do tema. 
Das gramáticas elencadas, destacamos uma citação de Cunha; Cintra (2001) que apresenta intuição a respeito do uso do ponto /./ para destacar informações em um texto e, consequentemente, do desgarramento:

O PONTO tem sido utilizado pelos escritores modernos onde os antigos poriam PONTO-E-VÍRGULA, ou mesmo VÍRGULA. Tratase de um eficiente recurso estilístico, quando usado adequada e sobriamente. Com a segmentação de períodos compostos em orações absolutas, ou com a transformação de termos destas em novas orações, obriga-se o leitor a ampliar as pausas entre os grupos fônicos de determinado texto, com o que lhe modifica a entoação e, consequentemente, o próprio sentido. As orações assim criadas adquirem um realce particular: ganham em afetividade e, não raro, passam a insinuar ideias e sentimentos, inexprimíveis numa pontuação normal e lógica"

(CUNHA; CINTRA, 2001, p. 651; grifos nossos)

Ao que os gramáticos denominam de "pontuação normal e lógica", Soncin; Tenani (2010) contrapõem o uso não-convecional da pontuação, aspecto que abordaremos a seguir.

Tenani; Soncin (2010) e Soncin; Tenani (2015) investigam a pontuação a partir do princípio de que "a heterogeneidade é constitutiva da escrita". Isto é, a escrita envolve um contiuum entre práticas orais e práticas letradas/ escritas que o escrevente vivencia.

As autoras analisam os empregos e não-empregos da vírgula em produções escritas de alunos do ensino fundamental para depreender as motivações dos usos desse sinal. Para tanto, abandonam uma abordagem normativa e assumem "uma perspectiva enunciativa, na qual o texto é produto da enunciação e o sujeito escrevente é o enunciador" (TENANI; SONCIN, 2010, p. 50). Assim, adotam o termo uso não-convencional para se referir aos usos da pontuação não referidos pela tradição gramatical. 
Sobre o uso não-convencional da vírgula, as autoras afirmam:

"[...] o dado não convencional se configura como lugar que possibilita discutir a complexidade do uso da vírgula como marca gráfica da heterogeneidade da escrita. Ao 'estar fora da convenção', o uso não convencional revela um funcionamento linguístico subjacente".

(SONCIN; TENANI, 2016, p. 480)

Assim como o uso da vírgula, o uso do ponto /./ para indicar o fenômeno do desgarramento pode ser entendido como um uso não-convencional que denuncia "a decisão do sujeito de não seguir a convenção por uma questão que extrapola os limites sintáticos e textuais e tem uma dimensão enunciativa" (TENANI; SONCIN, 2010, p. 51). Assim, Tenani; Soncin (2010) e Soncin; Tenani (2015) possibilitam o entendimento da pontuação a partir de uma perspectiva centrada no uso.

\section{Pressupostos teóricos}

Como já dissemos, os estudos de linha tradicional não contemplam a multiplicidade dos usos linguísticos do Português e, por isso, fenômenos como o desgarramento ficam fora de seu escopo. Portanto, para contemplar usos de estruturas desgarradas da língua - que são reais e efetivos - adotamos a abordagem funcionalista.

O funcionalismo tem como princípio básico observar e analisar a língua a partir de seus usos efetivos na interação. Nessa visão, a língua é um mecanismo vivo inserido em um contexto de comunicação e de interação logo, não há sentido em concebê-la de forma descontextualizada.

Nessa perspectiva, teóricos como Mathiessen; Thompson (1988) defendem que dentro de um texto há relações de organização (relações retóricas) que constroem o discurso como um todo, sendo a relação de núcleosatélite a que mais se relaciona ao nosso estudo. 
Segundo os autores, a sintaxe de um texto não se constitui apenas por coordenação ou por subordinação; algumas cláusulas estão ao redor como satélites - de um núcleo, porém não o constituem.

Já Hopper; Traugott (1993) propõem a análise da articulação de cláusulas a partir de um continuum envolvendo parataxe (coordenação), hipotaxe - correspondente às subordinadas adverbiais e as adjetivas explicativas da tradição - e subordinação - correspondente à subordinada substantiva e adjetiva restritiva da tradição. Os autores utilizam para explicar tais conceitos as noções de dependência e encaixamento: a dependência diz respeito à relação semântica entre os constituintes da sentença e o encaixamento à relação sintática entre eles, conforme ilustra o quadro 3:

Quadro 3. Continuum das categorias proposto por Hopper; Traugott (1993, p. 171)

\begin{tabular}{|ccccc|}
\hline Parataxe & $>$ & Hipotaxe & $>$ & Subordinação \\
- encaixamento & & -encaixamento & & + encaixamento \\
-dependência & & +dependência & & + dependência \\
\hline
\end{tabular}

Com base no quadro 3, pode-se afirmar que, na hipotaxe, a cláusula hipotática mantém um vínculo semântico com a nuclear, mas não sintático. Isso se dá porque as hipotáticas se combinam com as cláusulas nucleares, não sendo parte constituinte de outra como ocorre na subordinação.

Seguindo esse continuum, depreende-se que as hipotáticas são menos encaixadas do que as subordinadas e, por isso, Decat (2011) afirma que essas cláusulas se materializam desgarradas mais frequentemente.

\subsection{Desgarramento}

Como observado anteriormente, as noções funcionalistas de núcleosatélite e do continuum de articulação de cláusulas permitem compreender o que Decat (1993, 1999, 2001a, 2001b, 2004, 2008a, 2008b, 2009a, 2009b, 2011) denominou desgarramento. 
Segundo a autora, esse fenômeno

\begin{abstract}
“[...] refere-se, aqui, à ocorrência desgarrada de uma estrutura, produzida pelo falante/escritor já como uma estrutura não anexada sintaticamente ao que a antecede, e não, numa leitura gerativista, como uma estrutura que teria se desgarrado, se desprendido de uma 'estrutura-mãe'."
\end{abstract}

(DECAT, 2011, p.144)

A autora identifica como desgarramento os casos de cláusulas que ocorrem isoladas, independentes de suas cláusulas núcleos. Na escrita, como afirmado por Decat (2011) e ratificado nesse estudo, o uso do ponto /./ de forma não-convencional (SONCIN; TENANI, 2015) é indicador do fenômeno.

Para elucidar o fenômeno do desgarramento, Decat (2011) adota o conceito de unidade informacional, proposto por Chafe (1980). Segundo o autor, unidade informacional é um bloco de informação emitido de uma só vez, com sentido fechado e completo em si mesmo. Nesse sentido, uma hipotática desgarrada representa uma unidade de informação à parte, "um jato de linguagem", pois o escrevente a concebe como completa, produzindo-a como tal, ou seja, marcando sua independência com o ponto /./.

Para Decat (2009a, p. 130), o desgarramento funciona "como um mecanismo sintático a serviço da estratégia de focalização", que tem relação com a relevância do que se diz a respeito de alguma coisa. Portanto, a realização desgarrada de uma cláusula é a manifestação da necessidade de destacar/ focalizar uma informação para atribuir a ela maior peso discursivo. Por sua vez, esse destaque/foco está pragmaticamente a serviço da argumentação textual.

$\mathrm{O}$ exemplo a seguir ilustra a força argumentativa manifestada na ocorrência desgarrada de uma cláusula hipotática adverbial:

(2) Neste cenário desfavorável, alternativas surgem e animam o jovem estudante, como o sistema de cotas. Esta saída promete ao aluno uma perspectiva maior numa sociedade excludente em que é obrigado a lidar todos os dias. Ainda que a parte majoritária do país seja marcada pela pobreza.

Confluência. Rio de Janeiro: Liceu Literário Português, n. 61, p. 124-156, jul.-dez. 2021 
A cláusula em negrito no exemplo (2) contém uma ressalva ao tema debatido. Se a realização da hipotática não fosse desgarrada, o peso da argumentação seria mais atenuado/pouco expressivo. Ao conceber essa cláusula como sintaticamente independente, o escrevente opta por uma estratégia discursiva que concede ao seu argumento maior peso. Além disso, o desgarramento "contribui para a organização do fluxo informacional, colocando-se, portanto, a serviço da produção textual" (DECAT, 2009a, p. 121).

Ainda sobre o propósito discursivo do fenômeno, a autora investiga quais funções textual-discursivas exercem as cláusulas desgarradas em um texto, isto é, como a partir da sintaxe e da pragmática, o desgarramento auxilia na construção discursiva do texto.

A partir dessa investigação, a autora postula algumas funções textualdiscursivas desempenhadas pelas hipotáticas relativas apositivas e adverbiais (DECAT, 2009a; 2011), das quais destacamos adendo, avaliação, foco e retomada. Os exemplos seguintes elucidam tais funções (DECAT, 2009a;2011):

(3) No LanciaLybra, tudo foi pensado para melhorar a qualidade de vida. A começar pelo acolhimento que lhe reservamos, quando pedir para o experimentar. Uma vida de qualidade. (VISÃO - n. 343, Lisboa, 7 a 13 de outubro de 1999, p. 4)

(4) Um dos itens do último censo que mais provocaram comentários de especialistas e palpiteiros em geral foi a queda da "popularidade" da Igreja Católica no Brasil. Queda que vem se acentuando de censo a censo e que aparentemente coloca a chamada Nau de Pedro à beira do naufrágio no encapelado mar da modernidade. (CONY, Carlos Heitor. O gênero e o grau, Folha de São Paulo, Caderno Opinião, 26/05/02, p. A2) ${ }^{2}$

(5) Na hora agá, ela fraquejou. Não apareceu. Não pulou a janela com a trouxa. Ele acabou se afastando desiludido, mas começou a mandar cartas para elas através de um amigo. Que não as entregou. Ao contrário, guardou-as, começou a namorar a moça e logo casou-se com ela. (SANT'ANNA, Affonso Romano de. Fugir por amor, Estado de Minas, Caderno Cultura, $14 / 11 / 04$, p. 8$)$

2 O uso dessa desgarrada consiste em uma retomada; nos estudos de linguística textual 'Queda" está encapsulando toda uma porção do texto e é uma estratégia de referenciação denominada, por isso, de encapsulamento.

Confluência. Rio de Janeiro: Liceu Literário Português, n. 61, p. 124-156, jul.-dez. 2021 
(6) [...] Existem cidades actuais, modernas... e cidades que se adiantaram no tempo. Desenhadas para serem percorridas. Para nelas mergulharmos. (VISÃO, nº 342, 7 a 13 de outubro de 1999, p. 29)

A hipotática relativa apositiva desgarrada presente no exemplo (3) é, segundo a autora, um caso de avaliação; por meio da desgarrada se tece um comentário avaliativo sobre a porção de texto anterior. No exemplo (4), a função é de retomada, pois a cláusula retoma o que foi dito anteriormente. Em (5), a cláusula em destaque exerce função de adendo; ela é uma informação "dada tardiamente" (DECAT, 2009a). Por fim, no exemplo (6) tem-se a função de foco que, segundo a autora, é "materializada como realce, avaliação, ênfase, argumentação" (DECAT, 2009, p. 144). Pode-se entender essa função também como o "foco de culminância" do discurso, isto é, todo o movimento textual "deságua" na informação contida na cláusula com essa função.

Rodrigues (2019), ao acrescentar à análise de Decat (2011) a subcategorização do desgrramento em inerentemente pragmático, contextual e cotextual, reforça ainda mais essas funções textual-discursivas.

\subsection{Pontuação e argumentação}

Dahlet (2006) investiga os usos dos sinais de pontuação a partir dos processos que desencadeiam suas ocorrências. Diferentemente das gramáticas tradicionais, que apenas expõem e reproduzem modelos pré-estabelecidos de quando e como pontuar, a autora analisa os usos pontuacionais ${ }^{3}$ sem desvinculá-los da intenção comunicativa dos escreventes, pois "a pontuação se situa ao lado da escrita e da leitura, isto é, da produção e da recepção do sentido [...]" (DAHLET, 2006, p. 23).

A pontuação é concebida aqui a partir da análise dos seus usos textuais efetivos e de sua funcionalidade em cada contexto comunicativo escrito.

3 Dahlet (2006) cria o neologismo pontuacional - derivado de "da pontuação" - para evitar o uso contínuo do sintagma preposicional. 
Ressaltam-se as múltiplas possibilidades de pontuar um mesmo trecho e como cada possibilidade pontuacional pode evocar uma intenção discursiva distinta. Exemplo disso é o seguinte dado do corpus:

(7) Neste cenário desfavorável, alternativas surgem e animam o jovem estudante, como o sistema de cotas. Esta saída promete ao aluno uma perspectiva maior numa sociedade excludente em que é obrigado a lidar todos os dias. Ainda que a parte majoritária do pais seja marcada pela pobreza.

Em (7), o emprego do ponto /./ indica não só a autonomia sintática da cláusula hipotática adverbial em negrito, como também enfatiza sua argumentatividade por meio da segmentação; em outras palavras, evidencia o seu desgarramento. Em detrimento do uso do sinal de pontuação vírgula /,/ - sinal tradicionalmente prescrito para esse contexto - , esse uso nãoconvencional (TENANI, 2010) exemplifica a versatilidade da pontuação e o reflexo de sua utilização no discurso.

Na perspectiva de Dahlet (2006), os seguintes eixos são apresentados para discutir a natureza do fenômeno de pontuar: níveis de ocorrência da pontuação; sua função; e os tipos de sinais de pontuação e suas respectivas funcionalidades ${ }^{4}$. Além disso, os sinais de pontuação atuam em três níveis diferentes: nível de palavra, nível de frase e nível de texto, sendo o segundo mais importante para o presente estudo. Este nível corresponde não somente aos atos pontuacionais que ocorrem dentro de uma oração (como a vírgula /,/ ou o hífen /-/), como também aos que ocorrem dentro e entre períodos (as reticências /.../, o ponto-e-vírgula /;/ ou o próprio ponto /./).

Quanto à função, Dahlet (2006) afirma que a pontuação é um constituinte direto da produção do discurso escrito e sua ausência gera rupturas no ato comunicativo.

4 Utilizamos aqui função para remeter à função geral da pontuação e funcionalidade referindo-se às funções pontuais de cada sinal de pontuação em seus usos distintos.

Confluência. Rio de Janeiro: Liceu Literário Português, n. 61, p. 124-156, jul.-dez. 2021 
Um exemplo que ratifica essa propriedade da pontuação é o emprego da vírgula /,/ para distinguir as orações, nomeadas pela tradição, subordinadas adjetivas restritivas e adjetivas explicativas. Esse uso é explicitado em várias gramáticas tradicionais, como se observa no fragmento a seguir:

As RESTRITIVAS, como o nome indica, restrigem, limitam, precisam a significação do substantivo (ou pronome) antecedente. São, por conseguinte, indispensáveis ao sentido da frase; e, como se ligam ao antecedente sem pausa, dele não separam, na escrita, por vírgula.

$[\ldots]$

As EXPLICATIVAS acrescentam ao antecedente uma qualidade acessória, isto é, esclarecem melhor sua significação, à semelhança de um aposto. Aliás, por isso mesmo, não são indispensáveis ao sentido essencial da frase. Na fala, separam-se do antecedente por uma pausa, indicada na escrita por vírgula [...].

(CUNHA; CINTRA, 2001, p. 405 - 406; grifos nossos)

Nota-se que, na afirmação de Cunha; Cintra (2001), o único elemento que no âmbito da escrita distingue os tipos de subordinadas adjetivas é o uso da pontuação. Como apontam indiretamente os gramáticos, a presença ou ausência da vírgula /,/ modifica não só o estatuto sintático, como também altera a interpretação discursiva das orações em destaque, o que ratifica a afirmação de Dahlet (2006).

Quanto ao tipo dos sinais de pontuação, a autora separa-os em de pontuação de palavra - os sinais que atuam no nível da palavra; e de pontuação de frase, que, por sua vez, são separados em enunciativos e sequenciais, segundo sua funcionalidade.

Os sinais de pontuação com funcionalidade enunciativa são aqueles que indicam todas as formas de citação ou que promovem um efeito de sentido de distanciamento entre o enunciador e o enunciado (DAHLET, 2006, p. 51). 
Dentre eles estão: dois-pontos /:/, parênteses /( )/, ponto de interrogação /?/, ponto de exclamação $/ ! /$, reticências $/ . . . /$, duplos travessões $/-{ }^{5}$ etc.

Já os sinais com funcionalidade sequencial são assim denominados, pois delimitam um segmento de texto à esquerda e à direita, formando assim uma sequência. Segundo a autora, a alínea (espaço em branco entre um parágrafo e outro), o ponto/./, o ponto-e-vírgula/;/ e a vírgula/,/ "segmentam [...] o continuum da escrita, delimitam as sequências [...] e, por fim, hierarquizamnas" (DAHLET, 2006, p. 50). Nessa lógica, o sinal de maior amplitude é a alínea - pois delimita as maiores sequências (parágrafos), sendo seguida pelo ponto /./, ponto-e-vírgula /;/ e vírgula /,/.

No entanto, tanto a pontuação de palavra quanto a pontuação de frase podem assumir ainda outra dimensão. Por exemplo, o título do trabalho que fundamenta a teoria de Dahlet (2006) - As (man)obras da pontuação - apresenta o uso dos parênteses /( )/ em um funcionamento denominado pela autora enunciativo-pragmático. Ao utilizar o sinal para cortar a palavra "manobras", ampliam-se as possibilidades de interpretação do trecho, a saber: "as obras da pontuação"; "as manobras da pontuação"; ou, ainda, "as obrasmanobras da pontuação", veiculando assim sentidos não previstos por uma pontuação convencional.

Esse funcionamento pragmático-enunciativo só é possível, pois a pontuação é operadora sintática e semântica. Por atuar na sintaxe e na semântica do texto, pode atuar também em sua pragmática.

Assim como o parênteses /( )/, o ponto /./ também pode assumir um funcionamento pragmático-enunciativo como evidenciado por meio do exemplo (7). Ao destacar a cláusula (ao marcar o desgarramento), o sinal rematiza o segmento destacado e gera o peso argumentativo (DAHLET, 2006, p. 250), revelando assim uma intenção comunicativo-argumentativa presente nesse ato pontuacional.

5 A noção de rema aqui adotada corresponde à informação nova. 
No exemplo (8), o ponto /./ apresenta esse mesmo funcionamento:

(8) [Anthony Garotinho: meu governo] será um governo de rompimento com o atual modelo, que privilegia o capital especulativo em prejuízo dos que trabalham e produzem. Que privilegia os juros e persegue os salários. Que privilegia os interesses do capital internacional, em prejuízo do empresariado nacional. (F. S.P., 14.08.02 apud DAHLET, 2006, p.251; grifos meus)

As cláusulas em negrito estão desgarradas, portanto, rematizadas; sua força argumentativa, assim como sua independência sintática, é marcada pelo ponto $\% /$ de $\operatorname{argumentação~}{ }^{6}$.

(9) Neste cenário desfavorável, alternativas surgem e animam o jovem estudante, como o sistema de cotas. Esta saída promete ao aluno uma perspectiva maior numa sociedade excludente em que é obrigado a lidar todos os dias; ainda que a parte majoritária do pais seja marcada pela pobreza.

Poder-se-ia argumentar, contudo, que o uso do ponto-e-vírgula /;/ promoveria o mesmo efeito de sentido nesse contexto, como em (8). Entretanto, a presença do ponto-e-vírgula/;/ (de menor amplitude) em (9) estabelece ${ }^{7}$ um vínculo sintático com a porção de texto anterior e a argumentatividade da cláusula é drasticamente atenuada. Isso não significa que o ponto-e-vírgula /;/ não possa ser empregado com valor argumentativo, porém, em comparação, o ponto /./ de argumentação é muito mais produtivo.

Então, o ponto /./ é o sinal de pontuação de maior amplitude, depois da alínea. Por excelência, "anuncia que ali acaba algo e começa algo de novo" (DAHLET, 2006, p. 250) e é essa característica que motiva seu uso em detrimento dos demais sinais de sequência. Como evidenciado em (7)

6 Cf. Dahlet (2006), capítulo 10.

7 Ao contrário do que o nome transparece, as cláusulas desgarradas não se desafixaram de uma "estrutura-mãe". Elas são, por natureza discursiva, sintaticamente independentes. 
e (8), ele opera a favor da argumentação e isso é possível, porque seu grau de amplitude lhe permite "segmentar no coração da unidade sintáticosemântica" (DAHLET, 2006, p. 254), evidenciando a independência sintática das cláusulas.

Em suma, as cláusulas são desgarradas e o ponto é argumentativo, porque a natureza discursiva da argumentação no registro comunicativo escrito do Português Brasileiro os motiva a tal. Logo, não há "erro". Essas ocorrências estão antes relacionadas ao próprio estilo de escrita dos alunos, a estilística que constitui sua "escrevência".

\section{Metodologia}

Conforme dissemos, o corpus desse estudo foi coletado a partir de textos do banco de redações do site: educaçao.uol.com.br. A plataforma "Educação UOL" funciona como uma tutoria de produção textual online para estudantes que desejam realizar provas de vestibular. Os textos desses estudantes são submetidos ao site; eles são corrigidos, avaliados e comentados; após um mês, são postados no endereço eletrônico com a correção e a avaliação. Essas redações ficam disponíveis publicamente. Para esse trabalho, analisaram-se os textos postados de agosto de 2015 a junho de 2016; ao todo, foram analisadas cento e noventa e sete (197) redações de vestibulandos para a composição do corpus.

A investigação do desgarramento a partir desse tipo de texto (redações de vestibular) têm algumas motivações centrais: a) a produção textual nessa situação específica tende a ser mais monitorada, havendo menos liberdade de estilo. Verificar a produtividade do fenômeno nesse contexto nos permitiria, assim, depreender sua relevância como recurso linguístico; b) o desgarramento mostra-se produtivo em textos "que apresentam, em sua estrutura organizacional, sequências tipológicas argumentativas, dada a natureza de convencimento, de persuasão exibida 
por certos gêneros textuais" (DECAT, 2004, p. 86), como é o caso das redações de vestibular ${ }^{8}$.

Ao longo do estudo, houve tentativas de entrar em contato com a equipe do site para obter mais informações sobre os critérios de correção e nível de instrução dos corretores/avaliadores das redações, porém não tivemos sucesso nessa empreitada. Das cento e noventa e sete redações dissertativo-argumentativas analisadas, foram identificados dezenove (19) casos de cláusulas desgarradas, conforme já dissemos.

Os dados de desgarramento foram analisados a partir dos seguintes parâmetros: tipo de desgarrada - hipotática adverbial ou hipotática relativa apositiva; formato do introdutor - se há e qual introdutor que encabeça a desgarrada. Alguns introdutores comuns (DECAT, 2011): [.Que], [.O que], [.Conector] (este último para as hipotáticas adverbiais); função textualdiscursiva - adendo, avaliação, retomada e foco; tipo de sequência textual em que a desgarrada ocorre - descritiva, narrativa, argumentativa, injuntiva ou expositiva; elemento com o qual se articula - com um verbo, com uma oração, com um sintagma ou com uma porção de texto inteira; conteúdo semântico veiculado - esse fator só se aplica às hipotáticas adverbiais por já terem, por sua natureza adverbial, conteúdo semântico; modo verbal da cláusula - indicativo, subjuntivo, imperativo; status do introdutor - não prototípico, prototípico, híbrido ou não há introdutor; forma da cláusula - reduzida ou desenvolvida.

Após a leitura das redações, foram identificados dezenove (19) casos de cláusulas hipotáticas desgarradas, resultando em uma frequência de um caso a cada dez redações. Quanto ao tipo de desgarrada, contabilizaram-se

8 Redação de vestibular não é um gênero textual específico (cf. HASS; GUIMARÃES, 2014). Dá-se o nome genérico de redação ou composição a tudo o que se escreve; texto é uma unidade linguística comunicativa cujas sentenças estão ligadas por mecanismos de coesão e de coerência. Portanto, o texto não é um amontoado de frases justapostas e desorganizadas, mas uma construção organizada, um espaço de interação entre escritor/ leitor e o contexto em que esse se insere, além de revelar sempre uma intencionalidade (cf. PÉCORA,1983; GERALDI, 1984). 
doze (12) dados de hipotáticas relativas apositivas (doravante HRA) e sete (07) dados de hipotáticas adverbiais (doravante HA), como se observa pelo Gráficol. Portanto, 63\% (12 dados) do corpus é composto de HRA e 37\% (07 dados), de HA.

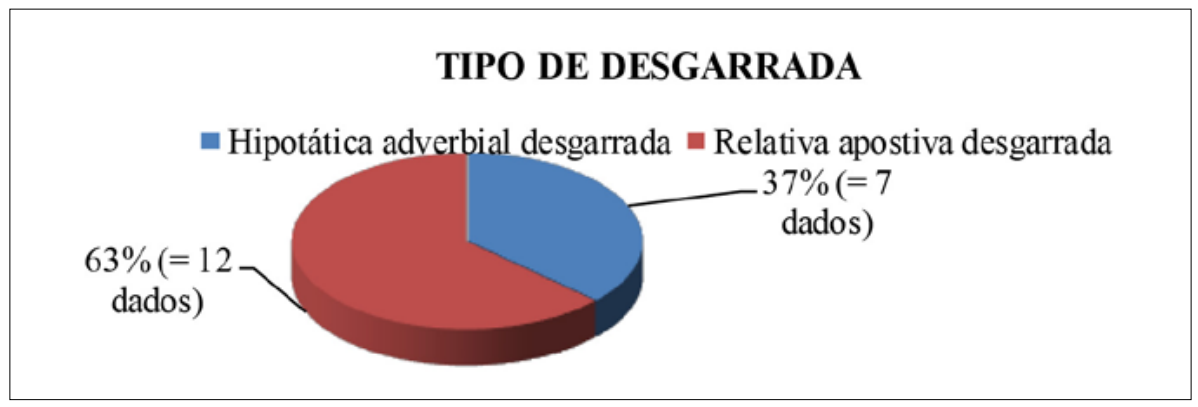

Gráfico 1. Tipo de desgarrada

Os exemplos seguintes ilustram dados do fenômeno em HRA e HA, respectivamente. A cláusula HRA exemplificada em (10) é iniciada por [. O que] e ilustra uma tendência observada no corpus (cinco (05) dados encabeçados pelo mesmo introdutor). $\mathrm{O}$ exemplo de HA é iniciado pelo conector prototípico "para que".

(10) Além disso, esse anseio exagerado em se tornar belo pode trazer inúmeros problemas de saúde. Na tentativa de encontrar o método mais barato, para manter a boa forma, o indivíduo acaba por ser entregue nas mãos de falsos médicos. O que devido a um trabalho mal feito ocasiona infecções, alergias, doenças mais graves e até mesmo morte.

(11)Evisto isso,éde extrema importância a manutenção de veículos que visema conscientização social a respeito do tema. Para que, progressivamente, se venha a disseminar as ilusões e contradições que existem no padrão atual que idolatra a estética física, e lentamente destrói a saúde, não apenas fisiológica, mas também mental. 
Embora não se tenha verificado nesse estudo o porquê da disparidade entre os dados de HRA e HA no corpus, segundo Decat (2001), pode-se apontar uma tendência de o desgarramento de estruturas iniciadas por [. $\mathrm{O}$ que]:

“...o pronome relativo que inicia o segmento oracional funciona como uma espécie de pronome resumidor, referindo-se a todo o texto anterior e não a um único elemento [...]. Essa função resumidora das adjetivas sem cabeças $^{9}$ é um fator semântico que contribui para que ocorram desgarradas."

(DECAT, 2001, p. 109)

Sobre os introdutores das estruturas HA desgarradas, verificaram-se dois (02) dados (28\%) de [.Gerúndio] e um (01) dado (29\%) de [.Conector] sendo esse o conector para que - e quatro (04) dados (43\%) com articuladores não-prototípicos, sendo eles: pois, visto que, além de e ainda que (cf. Gráfico 2).

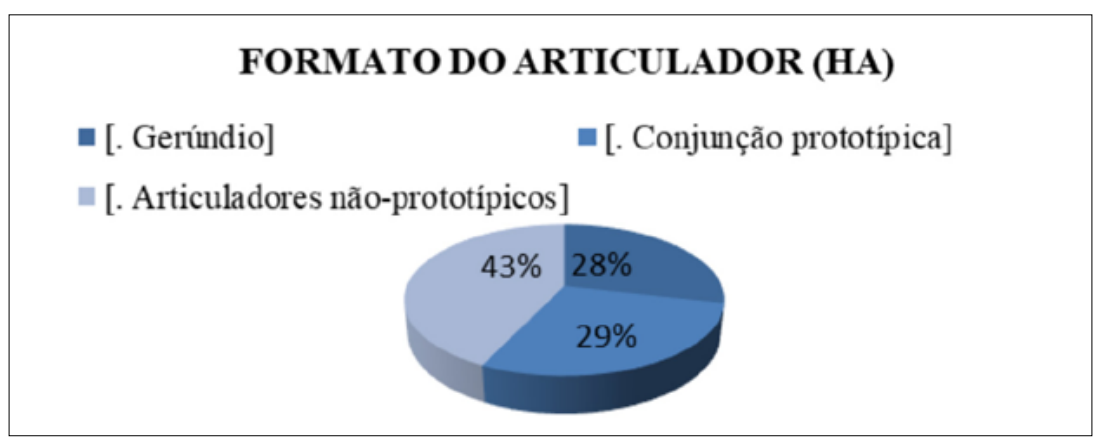

Gráfico 2. Formato do articulador (HA)

Quanto ao parâmetro "elemento com o qual a desgarrada se articula", obtiveram-se os resultados observados na Tabela 1. Dos doze (12) casos de HRA desgarradas, dez (10) mantém relação com toda a porção de texto

9 Isto é, das cláusulas hipotáticas relativas iniciadas por "o que".

Confluência. Rio de Janeiro: Liceu Literário Português, n. 61, p. 124-156, jul.-dez. 2021 
anterior, sendo cinco (05) casos de estruturas tipo [. O que] e cinco (05) casos de estruturas tipo [. Gerúndio]. Os outros dois (02) casos se articulam com um sintagma nominal e são de estruturas [. Que].

Tabela 1. Elemento com o qual a desgarrada se articula

\begin{tabular}{|l|c|c|}
\hline & Hipotáticas relativas apositivas & Hipotáticas adverbiais \\
\hline Porção de texto & 10 & 3 \\
\hline Cláusula & 0 & 4 \\
\hline Verbo & 0 & 0 \\
\hline Sintagma nominal & 2 & 0 \\
\hline
\end{tabular}

O exemplo a seguir ajuda a confirmar a afirmação de Decat (2001) sobre as estruturas [. O que] não terem referente explícito e/ou específico.

(12) Uma jovem de 16 anos, foi monstruosamente estuprada por 33 homens que a levaram desacordada para o local conhecido como "abatedouro". Além disso, um dos indivíduos utilizou seu perfil no Twitter para divulgar o ocorrido. O que nos faz pensar o quão longe pode chegar a maldade da raça humana. Além de ter acontecido essa monstruosidade, a jovem ainda foi violentada, como se não bastasse, os indivíduos ainda tiveram a crueldade de machucar a garota, deixando não só marcas sentimentais, mas físicas também.

Em (12), é impossível identificar se "o que nos faz pensar o quão longe pode chegar a maldade da raça humana" é a atrocidade do estupro coletivo sofrido pela jovem ou o fato do crime ter sido divulgado online. O pronome resumidor "o" (DECAT, 2001, p. 109) e o "que", aliados ao fenômeno do desgarramento e ao uso do ponto \% / de argumentação impossibilitam estabelecer um referente específico com o qual a desgarrada se articularia. Essa ausência referencial com essas estruturas reforça sua independência informacional, facilitando, portanto, sua ocorrência desgarrada.

Levando-se em conta que "o" artigo se origina do pronome do latim "ille" e o pronome tem função dêitica/mostradora, é possível essa 
interpretação. Além disso, o pronome pode ser um elemento de referenciação do tipo partícula encapsuladora, uma vez que recupera toda a informação anterior. No exemplo (12), "o que" recupera todos os eventos acontecidos com a jovem de 16 anos. Além disso, opera para a progressão textual, pois remete cataforicamente para a informação seguinte "a maldade da raça humana".

Outro caso de desgarrada introduzida pelo elemento de referenciação [ . O que] é o do exemplo (13), que ilustra uma ocorrência de HRA em sequência argumentativa e esta exerce exatamente função textual-discursiva de avaliação.

(13) Dessa forma a pesquisa da fosfoetanolamina deve ser incentivada e ampliada pelo governo, para que possam ser efetivadas como tratamento para o câncer. O que traria uma visão positiva para o Brasil como um país de realização. Haja vista que também e necessário a colaboração da sociedade brasileira com ONGs campanhas e incentivo para melhor uso do medicamento. Assim logicamente chegara-se a um consenso do uso do tratamento com a pílula.

O uso da desgarrada assevera o argumento proposto para a porção textual anterior. É importante ampliar a pesquisa da fosfoetanolamina, porque, além dos benefícios para os pacientes com câncer (argumento 1), também seria importante para a imagem internacional do Brasil, como afirma o argumento 2 presente na HRA.

A dificuldade de se identificar uma relação explícita com um elemento em particular se observa também em desgarradas iniciadas por [. Gerúndio]. Tanto nas HRA quanto nas HA iniciadas por essa forma nominal de verbo, não é possível recuperar uma referência explícita a um elemento. Dessa forma, o conteúdo informacional dessas desgarradas recai sobre toda porção textual que as precede. Poderíamos aqui também pensar em função encapsuladora do conector.

Dos três (03) casos de HA que se articulam com uma porção de texto na Tabela 1, dois (02) deles são de estruturas [. Gerúndio]. Nessas estruturas, a própria natureza da cláusula já dificulta o reconhecimento de um elemento com o qual ela se articularia. 
(14) O Governo, portanto, deve investir amplamente na educação da sociedade e pontualmente na conscientização da família acerca dos mecanismos de coibição contra a violência sexual. Oferecendo incentivo às empresas para financiar campanhas e projetos em prol dos adolescentes de baixa renda que vivem em situações preocupantes.

Em(14), apresenta-se a forma de ação proposta para o governo investir tanto na "educação da sociedade" quanto na "conscientização da família acerca dos mecanismos de coibição contra a violência sexual”. A posposição da HA aliada, novamente, ao ponto /./ de argumentação condicionam o conteúdo semântico de modo que recai sobre toda a informação anterior " $\mathrm{O}$ governo deve investir amplamente na educação da sociedade e pontualmente na conscientização da família acerca dos mecanismos de coibição contra a violência sexual."

Além de retomada, as cláusulas desgarradas exercem ainda função textual-discursiva de adendo, avaliação e foco.

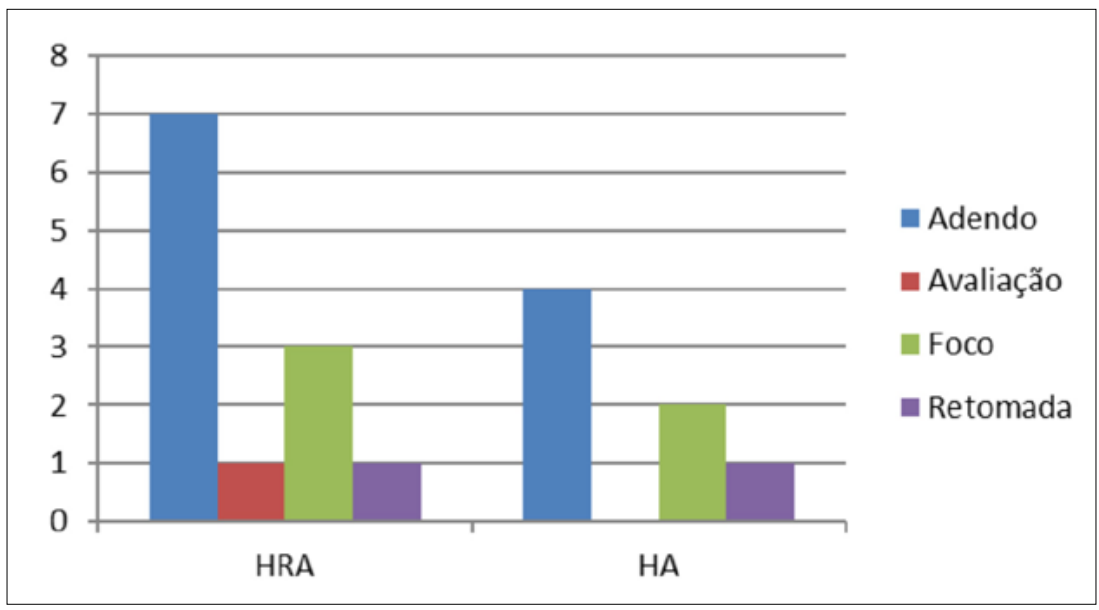

Gráfico 3. Função textual-discursiva

O gráfico 3 mostra as funções textual-discursivas das HRA e das HA: a função mais frequente é a de adendo com onze (11) ocorrências (sete (07) casos em HRA e quatro (04) casos em HA); as ocorrências de foco são cinco 
(três (03) casos em HRA e dois (02) em HA). A seguir, ilustramos casos de HA com função de adendo e foco.

(15) Neste cenário desfavorável, alternativas surgem e animam o jovem estudante, como o sistema de cotas. Esta saída promete ao aluno uma perspectiva maior numa sociedade excludente em que é obrigado a lidar todos os dias. Ainda que a parte majoritária do pais seja marcada pela pobreza.

(16) Segundamente a aprovação no Congresso Nacional sofreu grande pressão popular, já que todo paciente diagnosticado com neoplasia maligna, por natureza humana, seria capaz de ingerir qualquer remédio que pudesse apresentar melhora, por menor que fosse. Ignorando assim, todos os efeitos colaterais que a droga pode oferecer.

Em (15), a cláusula "Ainda que a parte majoritária do país seja marcada pela pobreza" enfatiza a informação sobre a cota como uma saída que promete ao aluno uma maior perspectiva de vida.

A desgarrada destacada em (16) é o ponto de culminância do discurso. Todos os apontamentos feitos ao longo do trecho resumem-se na cláusula adverbial, que funciona, portanto, como o foco do texto.

Além dessas duas funções, houve ainda um (01) caso de avaliação e dois (02) casos de retomada. Para melhor elucidar o caso de avaliação, porém, é interessante analisá-los em cotejo com as informações trazidas pela tabela 2 a seguir (referente ao parâmetro de análise 4, "tipo de sequência em que a desgarrada ocorre):

Tabela 2. Tipo de sequência na qual a desgarrada ocorre

\begin{tabular}{|l|c|c|}
\hline & Hipotáticas relativas apositivas & Hipotáticas adverbiais \\
\hline Expositiva & 7 & 0 \\
\hline Descritiva & 4 & 1 \\
\hline Argumentativa & 1 & 0 \\
\hline Injuntiva & 0 & 0 \\
\hline Narrativa & 0 & 6 \\
\hline
\end{tabular}


Pode-se observar que a maioria das HRA não ocorre em sequências argumentativas, como se esperaria de redações de vestibulandos. Isso porque muitas dessas redações se propõem argumentativas, porém acabam tendo mais sequências expositivas ou descritivas. A seguir um trecho expositivo:

(17) Os avanços tecnológicos das últimas décadas estão cada vez mais notórios e mais integrados ao nosso cotidiano. As mudanças trazidas por essa nova etapa da história da humanidade, que já é chamada por alguns de quarta revolução industrial, tem influenciado assim como as anteriores, as taxas de desemprego da população. Deixando obsoletas várias funções antes ocupadas por uma grande parte de trabalhadores. Remanescendo apenas aqueles cujo o perfil se enquadra nas novas necessidades.

Em um texto argumentativo, podem aparecer sequências de outras tipologias textuais, visto que as sequências que integram os textos são tipologicamente variadas. Assim, na redação de vestibular podemos encontrar tanto sequências expostivas quanto argumentativas. Nesse sentido vale elucidar a diferença entre dissertação/exposição e argumentação. A dissertação/exposição se propõe ao convencimento, pois visa a atingir a razão, o racional, o lado esquerdo do cérebro. Atinge a um auditório universal, já que as proposições não são, em princípio, questionáveis. Já a argumentação se propõe à persuasão, uma vez que visa a atingir o emocional, o paralógico (aquilo que está ao lado da lógica) e lida com elementos ligados ao desejo, às crenças, de modo a conseguir a atenção de um auditório particular. Um texto dissertativo-argumentativo (como o da redação de vestibular) utiliza tanto o convencimento quanto a persuasão para fazer o receptor aderir à tese apresentada. Assim, exposição, narração e descrição aparecem na redação, com a função de sustentar os argumentos propostos para validar a tese.

O exemplo (17) antes exemplificado é, portanto, expositivo e, portanto, visa ao convencimento e pode estar a serviço da argumentação. Esse fato confirma a postulação de Decat (2004) sobre o fato de o desgarramento não ser: 
uma estratégia argumentativa específica de determinado gênero ${ }^{10}$, ou seja, dependendo não só do suporte linguístico que veicula a informação, como também do domínio discursivo em que um gênero se insere, é possível ocorrerem ou não, estruturas do tipo que está sendo analisado. (DECAT, 2004, p.86)

As sequências nas quais as HA ocorrem são em sua maioria sequências textuais argumentativas. Isso se justifica pela própria natureza das cláusulas adverbiais. As seis (06) HA que ocorrem em sequências argumentativas têm conteúdo semântico de: finalidade, modo; dois (02) casos de causa, consequência e modo novamente - respectivamente encabeçadas por: [. Para], [. Além de], [. Visto que], [. Pois], [. Gerúndio] e [. Gerúndio] novamente. A única HA que ocorre em sequência textual descritiva é encabeçada por [. Ainda que] e tem conteúdo semântico de concessão.

Assim como aconteceu em Rodrigues (2019), que analisou postagens do Facebook, as hipotáticas relativas apositivas e as adverbiais são desgarradas que tendem a ser cotextuais porque estabelecem relação com porções textuais materializadas antes delas. Já as insubordinadas tendem a vir totalmente soltas, como acontece com as completivas não abordadas aqui.

Com base na análise dos resultados antes apresentados, podese perceber que o desgarramento é um fenômeno que ocorre em redações de vestibulandos, ainda que sejam textos que envolvam considerável monitoramento linguístico.

\section{Conclusão}

Após a análise dos resultados, verifica-se que o ponto $\%$ / de argumentação é o principal índice do fenômeno do desgarramento e a partir da ocorrência das cláusulas hipotáticas isoladas pela pontuação, o escrevente não só modifica a estrutura sintática do texto como também seu sentido.

10 Retomo Hass; Guimarães (2014) sobre redação de vestibular não ser um gênero específico.

Confluência. Rio de Janeiro: Liceu Literário Português, n. 61, p. 124-156, jul.-dez. 2021 
Entendendo que à Estilística pertence o conjunto de elementos linguísticos de que o escrevente se utiliza para veicular uma informação, o desgarramento $e$ o uso da pontuação aqui se revelaram ferramentas efetivas do processo de escrita e da argumentação.

Com isso, confirma-se a postulação de Dahlet (2006) de que a pontuação é operadora sintática e semântica. Além disso, ratifica-se que a cláusula hipotática desgarrada é "produzida pelo falante/escritor já como uma estrutura não anexada sintaticamente ao que a antecede e não [...] como uma estrutura que teria se desgarrado, se desprendido de uma "estrutura-mãe" (DECAT, 2011 p. 114).

No que se refere aos textos investigados, verificou-se uma preferência por HRA (12 casos) em detrimento das HA (7 casos), porém esse estudo não traz respostas sobre o porquê dessa disparidade. Talvez isso possa ser objeto de futuras investigações. Observou-se ainda uma maior ocorrência de hipotáticas apositivas introduzidas por [. O que] (relativas sem cabeça - DECAT, 2011) e hipotáticas reduzidas de gerúndio, que compõe $40 \%$ (07 dados) do corpus.

Por fim, os dados apresentados por esse estudo demonstram o uso do desgarramento e seu poder ilocucionário no todo textual. A partir disso, fica clara a necessidade de reformular as perspectivas e estratégias de ensino da sintaxe do Português nas escolas brasileiras, de forma prestigiar uma visão que permita maior reflexão e autonomia aos alunos em suas produções textuais, usando as diferentes normas do Português.

\section{Referências}

BECHARA, E. Moderna gramática portuguesa. 37. ed. rev. e ampl. Rio de Janeiro: Lucerna, 2003.

CATACH, Nina. La ponctuation. Paris: PUF, 1994.

CHAFE, W. L. The deployment of consciousness in the production of a narrative. In: CHAFE, W.L. (ed.). The Pear Stories: cognitive, cultural, and linguistic aspects of narrative production. Norwood: Ablex, 1980. 
CIDADE, David Novaes. Desgarramento de cláusulas hipotáticas em redações de vestibulandos. Monografia de Final de Curso de Graduação em Letras Português - Alemão, Rio de Janeiro, Universidade Federal do Rio de Janeiro (UFRJ), 2020.

CUNHA, C.; CINTRA, L. F. L. Nova gramática do português contemporâneo. $3^{\text {a }}$ ed. Rio de Janeiro: Nova Fronteira, 2001.

DAHLET, V. As (man)obras da pontuação: usos e significações. São Paulo: Associação EditoralHumanitas, 2006.

DECAT, M. B. N. Leite com manga morre: da hipotaxe adverbial no português em uso. Tese de Doutorado em Linguística Aplicada ao Ensino da Língua. São Paulo, LAEL/PUC, 1993.

. Por uma abordagem da (in)dependência de cláusulas à luz da noção de “unidade informacional”. Scripta (Linguística e Filologia), v. 2 n. 4, Belo Horizonte: PUC Minas, 2º sem, p. 23-38, 1999.

. A articulação hipotática adverbial no português em uso. In: DECAT, Maria Beatriz Nascimento et al. Aspectos da gramática do português. Campinas: Mercado de Letras, 2001.

. Orações adjetivas explicativas no português e no português europeu: aposição rumo ao 'desgarramento'. Scripta (Linguística e Filologia), vol. 5, no 9. Belo Horizonte: PUC Minas, $2^{\circ}$ sem 2001a, p. 104-118.

. Orações relativas apositivas: SNs 'soltos' como estratégia de focalização e argumentação. Veredas (Conexão de orações), vol. $8, \mathrm{n}^{\circ} 1 \mathrm{e}$ 2, jan./dez. 2004. Juiz de Fora, MG: Editora UFJF, p. 79-101.

A hipotaxe adverbial em português e sua materialização como estruturas desgarradas. (Descrição do Português). VIII Seminário em Linguística e Língua Portuguesa, Araraquara, UNESP, 2008. 
A função focalizadora de estruturas desgarradas no português falado e escrito: um estudo funcionalista de orações em sua ocorrência como enunciado independente. II Simpósio Mundial de Estudos de Língua Portuguesa - SIMELP, Universidade de Évora, Évora-Portugal, outubro de 2009a: www.simelp2009.uevora.pt/pdf/slg5/08.pdf

- A hipotaxe adverbial em português: materializações e funções textual-discursivas. II Simpósio Mundial de Estudos de Língua Portuguesa - SIMELP, Universidade de Évora, Évora-Portugal, outubro de 2009b: www.simelp2009.uevora.pt/pdf/slg41/07.pdf

- Estruturas Desgarradas em Língua Portuguesa.

Campinas, SP: Pontes Editores, 2011.

GERALDI, João Wanderley. O texto na sala de aula - leitura \& produção. 3. ed., Cascavel, ASSOESTE, 1984.

HASS, D. D.; GUIMARAES, A, M. M; Redação de vestibular: um gênero de texto?/Composition of the university entrance exam: A textual genre? Revista Entrelinhas - vol. 8, $\mathrm{n}^{\mathrm{o}}$ 1, jan./jun. 2014: http://revistas.unisinos.br/index.php/ entrelinhas/article/view/82/4275

ROCHA LIMA, C. H. Gramática normativa da língua portuguesa. 45. ed. Rio de Janeiro: José Olympio, 2006.

LUFT, C. P. Moderna gramática brasileira. (supervisão: Lya Luft; organização: Marcelo Módolo; consultoria técnica: Mário Eduardo Viaro) 2. ed. rev. e atual. São Paulo: Globo, 2002.

HOPPER, Paul; TRAUGOTT, Elizabeth Closs. Grammaticalization across clause. In: Grammaticalization. CUP: Cambridge, 1993.

MATTHIESSEN, Christian; THOMPSON, Sandra A. The structure of discourse and 'subordination'. In: HAIMAN; THOMPSON (Ed.). Clause combining in grammar and discourse. Amsterdam: John Benjamins Publishing, 1988. 
PÉCORA, Alcir. Problemas de redação. São Paulo, Martins Fontes, 1983. site educacao.uol.com.br

RODRIGUES, Violeta Virginia (org.). Articulação de orações: pesquisa e ensino. Rio de Janeiro, UFRJ, 2010.

RODRIGUES, Violeta Virginia (org.). Articulação de orações: pesquisa e ensino. Rio de Janeiro: UFRJ, 2017. 210p. ISBN: 978-85-93916-00-7 Link para o download do livro no site da Pós de Letras Vernáculas: http://posvernaculas. letras.ufrj.br/index.php/publicacoes

RODRIGUES, Violeta Virginia. Desgarramento de cláusulas em português: usos e descrição (org.). São Paulo: Blucher, 2019. Disponível gratuitamente em www.blucher.com.br

SONCIN, Geovana e TENANI, Luciani. Emprego de vírgula e prosódia do Português Brasileiro: aspectos teórico-analíticos e implicações didáticas. Filol. Linguíst. Port., São Paulo, v. 17, n. 2, p. 473-493, jul./dez. 2015. http:/ dx.doi.org/10.11606/issn.2176-9419.v17i2p473-493.

SONCIN, G.; TENANI, L. Emprego de vírgula e prosódia do Português Brasileiro: aspectos teórico-analíticos e implicações didáticas. In: Filologia e Linguística Portuguesa, 17(2), 473-493, 2016. https://doi.org/10.11606/ issn.2176-9419.v17i2p473-493

TENANI, L. E.; SONCIN, G. C. N. O emprego de vírgulas: evidências de relações entre enunciados falados e escritos. In: II Simpósio Mundial de Língua Portuguesa, 2010, Évora. Estudos de Língua Portuguesa: ultrapassar fronteiras, juntar culturas. Évora: Universidade de Évora. v. 01, 2010. 44-65p. 